\title{
A RATIONALE FOR ACKNOWLEDGING THE DIVERSITY OF LEARNER ACHIEVEMENTS IN LEARNING PARTICULAR LANGUAGES IN SCHOOL EDUCATION IN AUSTRALIA
}

\footnotetext{
Angela Scarino Research Centre for Languages \& Cultures, University of South Australia Angela.Scarino@unisa.edu.au

In school languages education in Australia at present there is an increasing diversity of languages and learners learning particular languages that results from a greater global movement of students. This diversity builds on a long-established profile of diversity that reflects the migration history of Australia. It stands in sharp contrast to the force of standardisation in education in general and in the history of the development of state and national frameworks for the learning of languages K-12 in Australia and indeed beyond. These frameworks have characteristically generalised across diverse languages, diverse learner groups and diverse program conditions, in particular, the amount of time made available for language learning. In addition, in the absence of empirical studies of learner achievements in learning particular languages over time, the development of such frameworks has drawn primarily on internationally available language proficiency descriptions [such as the American Council for the Teaching of Foreign Languages (ACTFL), the International Second Language Proficiency Rating Scale (ISLPR), and more recently the Common European Framework of Reference (CEFR)] that were developed primarily to serve reporting and credentialing rather than learning purposes.
}

Drawing on a description of the current context of linguistic and cultural diversity and on a brief characterisation of the history of curriculum and assessment framework development for the languages area, I provide a rationale for acknowledging in the development and use of frameworks (i.e. descriptions of achievements) the diversity of languages that comprise the languages learning area in Australia and, in particular, the diverse learner groups who come to their learning with diverse experiences of learning and using particular languages. The Student Achievement in Asian Languages Education (SAALE) study provides an example of the development of descriptions of achievement that are sensitive to these dimensions of context. I discuss the rationale for such context-sensitive descriptions in relation to their potential purposes and uses at the language policy and planning and educational systems level, at the teaching and learning level, and in ongoing research.

KEY WORDS: language learner achievements, linguistic and cultural diversity, Asian languages, community/heritage languages 


\section{INTRODUCTION: THE NEED TO ADDRESS THE QUESTION OF THE DIVERSITY OF LEARNER ACHIEVEMENTS IN ASIAN LANGUAGES}

The Student Achievement in Asian Languages Education (SAALE) project (Scarino et al., 2011) was the first study undertaken in Australia to investigate and develop descriptions of student achievements for diverse learner groups learning languages in schools from kindergarten through to Year $12(\mathrm{~K}-12)$. It addressed the question of what it is that students actually achieve as a result of learning particular Asian languages (Chinese, Indonesian, Japanese and Korean). It also addressed the question of how well they achieve this learning, that is, it sought to describe the qualitative nature and the level or standard of achievement. It addressed these two questions in relation to (1) diverse learner backgrounds relative to the target language and (2) varying time-on-task in the experience of language learning. As such, it responded to the need in languages education for baseline data on student achievements for different groups of learners at different points along the $\mathrm{K}-12$ continuum of schooling. This need is relevant not only at state and national levels but also at the level of individual programs. It is potentially of interest to all those involved in languages education in schools students, teachers, parents and school communities, education systems, language policy makers, teacher educators and researchers.

At the present time in Australia the question of student achievements, particularly in Asian languages education, is pertinent to systemic language education policy development because of the Australian government's prioritisation of the languages of Asia (specifically Chinese, Japanese, Indonesian and Korean) in school languages education. For the government and the wider community, this prioritisation has re-animated accountability questions about student learning outcomes relative to educational policy investment. At the same time, these languages present distinctive challenges in the Australian context for a number of reasons, including, for example, their distinctive place in the history of languages education in Australia; the diversity of learners and their varying needs, interests and aspirations in learning these languages; and the linguistic and cultural distance from English as the national and first language of second language learners.

The question of the nature, scope and quality of student achievements in these languages across the K-12 continuum is particularly complex. Despite its inclusion in the Melbourne Declaration on Educational Goals for Young Australians (Ministerial Council on Education, Employment, Training and Youth Affairs [MCEETYA], 2008), the languages learning area is not a core curricular area of learning for all students and it cannot be assumed that all students engage in continuous language learning over extended periods of time; indeed, language learning can begin and end at any point along the $\mathrm{K}-12$ continuum. Furthermore, students interested in learning these languages at school include those studying the target language as an additional (or second) language, those studying their first language, and those studying a language in which they have some home background. This situation places

232 A RATIONALE FOR ACKNOWLEDGING THE DIVERSITY OF LEARNER ACHIEVEMENTS IN LEARNING PARTICULAR LANGUAGES IN SCHOOL EDUCATION IN AUSTRALIA 
pressure on educational systems and teachers to respond in ways that are often generalised with respect to curriculum, teaching, learning and assessment provisions and therefore conceal the nature, scope and quality of student achievements. In educational terms, this generalised response provides a weak basis for supporting the ongoing recognition and development of student achievements in learning particular Asian languages.

In this paper I describe firstly, the current context of increasing diversity of languages and learners learning particular languages. I then provide a brief characterisation of the history of curriculum and assessment framework development for the languages area and its force towards standardisation. Noting the tension between this diversity on the one hand and standardisation on the other, I provide a rationale for acknowledging the diversity of learner achievements in learning particular languages in school education. I draw upon the SAALE study to illustrate how achievements that are sensitive to at least the two major dimensions of context of language learning in Australia (specifically learner background and time-on-task) might be developed. I discuss the rationale in relation to purposes at the policy and educational systems level, at the teaching and learning level and in ongoing research. I conclude with a discussion of the need to focus on understanding learner achievements developmentally across the K-12 continuum for it is this understanding that shapes expectations which, in turn, shape the nature, scope and quality of language learning itself and its ongoing improvement.

\section{CONTEXT FOR DESCRIBING STUDENT ACHIEVEMENTS IN AUSTRALIAN SCHOOL LANGUAGE EDUCATION}

Two aspects of the context for describing student achievements in learning languages need to be highlighted. These are: (1) the increasing diversity of languages and students in educational communities and (2) the history of the development of curriculum and assessment frameworks for learning languages.

\section{INCREASING DIVERSITY OF LANGUAGES AND STUDENTS IN EDUCATIONAL COMMUNITIES}

Current trends show an increasing movement of students globally. This is the result of the dynamic, voluntary or forced migration of families, as well as student mobility that is part of various forms of international education and study-abroad programs. In addition, there is an unprecedented use of the internet and mobile technologies in all aspects of everyday life, which expands the range and diversity of potential networks for communication and exchange. This movement and these technologies have a marked impact on education in general and on languages education in particular, as students move and learn across both local and global, linguistic and cultural contexts; they bring to communities an increasingly diverse range of languages and ways of using them. The educational system in Australia has responded and needs to continue to respond to the resulting diversity of learners of languages

A RATIONALE FOR ACKNOWLEDGING THE DIVERSITY OF LEARNER ACHIEVEMENTS IN LEARNING PARTICULAR LANGUAGES IN SCHOOL EDUCATION IN AUSTRALIA 233 
in the community and in classrooms. (See Scrimgeour, this volume). It needs to acknowledge that students come to education in general and to languages education in particular with diverse linguistic, cultural, social and personal life-worlds, with unique trajectories of experiences, knowledge and values and with diverse motivations and expectations in relation to learning particular languages. These unique histories are not only a part of the context of learning but they are also constitutive of learning (Scarino, 2010). In languages education, programs are needed that take into account students' relationship with the target. Community languages education in Australia (Clyne 1991, 2005), like heritage language education in the USA (Brinton, Kagan \& Bauckus, 2008; Peyton, Ranard \& McGinnis, 2001), are intended specifically to provide programs for students who have a home background in the target language. In Australia many of the languages offered in Australian mainstream education and in the various community or ethnic schools are languages that are represented in the Australian community, adding diversity in terms of the contexts, nature and extent of exposure to the target language.

Stroud and Heugh (2011) explain that the movement of people also changes the very nature of multilingualism, of language and language learning in contemporary times. They state:

Classrooms and curricula need to be able to engage with and build on the diversity in
semiotic modes that learners bring into the classroom ... The shifting nature of learner
personae and subjectivities point toward the need for new understandings of the
teaching/learning process ... particularly its individuation to accommodate different
types of learner biographies emanating from the heterogeneity of learning
environments and biographies, social trajectories, and related interactional experiences
of speakers/learners (Stroud \& Heugh, 2011, p.424)

As part of this need to reconsider the teaching and learning process, (see also Lo Bianco 2009) there is a related need to reconceptualise the nature, scope and quality of learning achievements of diverse groups of learners (McNamara \& Elder, 2010).

In any particular educational community it becomes necessary to take into account the macro features of the ecology of languages in use in that particular context. For example, in Australia, Chinese now is the most widely spoken language after English. As Orton (2008, p.4) explains, in Australia China is seen as:

a regional neighbour, its largest trading partner, a rising world economic power, a major source of immigrant workforce, a major source of international students, a major source of tourists to Australia, a major source of destination for Australian tourists, the biggest source of immigrant settlers, a country with a long and prestigious culture, home to one in five human beings on earth.

234 A RATIONALE FOR ACKNOWLEDGING THE DIVERSITY OF LEARNER ACHIEVEMENTS IN LEARNING PARTICULAR LANGUAGES IN SCHOOL EDUCATION IN AUSTRALIA 
The long history of migration from China to Australia has shaped the history of Chinese language learning in school education in Australia. Over time, provision has been made in response to the changing linguistic and cultural context. For example, in South Australia, Chinese was first introduced at senior secondary level in 1972. (See Mercurio \& Scarino, 2005 , for a full discussion of the introduction of the languages of migrants). Because of the changing profile of the groups of students learning Chinese that results from the ecology of use of Chinese in Australia, over time, differentiated courses have been made available for second language learners and background speakers of Chinese at Years 11 and 12, with complex 'eligibility criteria' which seek to, but do not always, ensure that students of Chinese take the course that is most appropriate for them. Such provision, however, is not normally available in the K-10 years, and yet it is clear that at all levels in Australian languages education, students will come to the learning of Chinese with markedly different background profiles in and affiliation to the target language. The Australian context for the learning of Chinese is markedly different, for example, from the Singaporean context where Chinese is one of languages that is taught in the context of the compulsory mother tongue language policy (Stroud \& Wee, 2010). As indicated in this example for the learning of Chinese, the contexts in which particular languages are made available will differ because of factors such as dynamic migration histories, international relations and educational policies. The resulting status of each particular language in the ecology of languages in the specific educational context in which it is made available will influence learner achievements.

\section{THE DEVELOPMENT OF CURRICULUM AND ASSESSMENT FRAMEWORKS FOR LEARNING LANGUAGES}

Over the past three decades in Australian education, there has been a continuous development of curriculum and assessment frameworks that seek to describe learner achievements (see Scarino, 2000 and 2008 for a more detailed description than can be provided here.) At a national level this began in the mid-1980s with the development of The Australian Languages Levels (ALL) Guidelines (Scarino, Vale, McKay\& Clark, 1989). Its initial purpose was to describe graded levels of achievement in learning languages. A framework of stages was developed to take into account students' home background and prior language learning experience. Based on this work and considering the needs of senior secondary level of schooling in particular, the National Assessment Framework for Languages at Senior Secondary Level (Australasian Curriculum, Assessment and Certification Authorities [ACACA], 1991) was developed. This was followed by the Collaborative Curriculum and Assessment Framework for Languages (ACACA, 2001). These frameworks have been used nationally to provide the bases for developing different syllabuses and courses to cater for the diverse groups of learners. At that time, a generic curriculum framework was developed in order to provide for learning an increasing range of languages from $\mathrm{K}-12$, and to cater for diverse groups of learners with diverse sociocultural and linguistic profiles. This particular kind of framework provided a set of broad principles

A RATIONALE FOR ACKNOWLEDGING THE DIVERSITY OF LEARNER ACHIEVEMENTS IN LEARNING PARTICULAR LANGUAGES IN SCHOOL EDUCATION IN AUSTRALIA 235 
and guidelines for developing curriculum and for assessment. It was intended to provide a conceptualisation of the languages curriculum and assessment as a whole. Despite pressure to do so, it did not provide generalised descriptions of the nature, extent and quality of anticipated achievements that have become the norm in subsequent developments. This was because the priority was the development of a conceptual framework that captured the commonalities in learning languages; learner achievements for diverse learner groups were per force not common across languages.

Since the 1990s there has been a continuous process of developing national and state-based curriculum and assessment frameworks for languages that include descriptions of student achievement. These mirror a direction in education as a whole towards standardisation in the interests of accountability based on 'outcomes' and most recently extending to the international monitoring of standards through programs such as the literacy assessment in the Program for International Student Assessment (PISA) (see, for example, Ball, 2000; Luke, 2011). The nationally developed Profile for Languages (Curriculum Corporation of Australia 1994) provides an example of one such framework which was subsequently used to inform state-based framework development in different states and territories of Australia (see for example Board of Studies of Victoria, 1995). The Profile described the 'outcomes' of learning at eight levels. Levels 4 and 5 for oral interaction, for example, stated:

4.1 Interacts in familiar social and learning situations, using familiar language with some flexibility

5.1 Interacts in familiar social and learning situations, using connected speech to respond to longer and continuous spoken texts.

These generalised descriptions were intended to be used by teachers of all languages to inform curriculum and assessment practices (see Scarino, 1995 for a critical discussion). In current times the Common European Framework of Reference (Council of Europe, 2001), which is becoming increasingly influential in Europe and beyond, extends the generalisation and standardisation to a global level (McNamara \& Elder, 2010).

These kinds of frameworks have all been generic; firstly in the sense of generalising across specific languages (with diverse grammars and orthographies and relative learnability for diverse students); and secondly by generalising across learners (with diverse background profiles in relation to the target language) and conditions and cultures of learning (involving diverse amounts of time-on-task). This degree of generalisation, however, has led to the standardisation of content and descriptions of achievement across languages. Although this kind of generic framework approach has the important advantage in the Australian context of languages education of allowing for the inclusion in school education of the diverse languages that are available in the community, the force of standardisation means that achievements are addressed in a way that is less than meaningful for systems, for teachers,

236 A RATIONALE FOR ACKNOWLEDGING THE DIVERSITY OF LEARNER ACHIEVEMENTS IN LEARNING PARTICULAR LANGUAGES IN SCHOOL EDUCATION IN AUSTRALIA 
for students and for the wider community. This standardisation masks the very real differences in learner achievements that result from the nature of the different languages (for example, whether the language is alphabetic or non-alphabetic and therefore its relative learnability for different groups of students) and what it is that students of particular languages with different learner backgrounds are expected to learn. It also masks the different conditions available for language learning (e.g. time-on-task). The differences in achievements are differences in nature, scope and levels of achievement. Because this standardisation has been established and maintained in languages education for more than two decades, it has also shaped the expectations of all involved about what students should do and in fact learn at different phases along the K-12 continuum.

The highly generalised descriptions of learners' achievements that are currently available do not provide a sufficiently meaningful response to the question of learner achievements. Any statement about learner achievements needs to be qualified to take account of important features of the context. For example, when speaking about the success of students learning languages at Year 12 level, it is important to know that there are differences in the expected and actual achievements of different groups of learners. It is a well-known phenomenon in languages education in Australia that when L2 learners of Chinese, for example, perceive that they are "in competition with" L1 or background learners of Chinese, this acts as a disincentive to their continued learning. Equally, from the L1 learner perspective, their actual achievements need to be acknowledged and built upon rather than adjusted through scaling processes implemented to act as an equalising force to address the perceived 'advantage'. (See Elder 2000a and 2000b for a detailed discussion; Orton, 2008).

To date, there has been no formal national assessment in languages and no requirement for teachers to report learner achievements in languages using the current generic descriptions of achievement. If a national assessment were to be implemented it would not be feasible to provide achievement data without qualification. For example, in consultations undertaken in all states and territories of Australia as part of the study that led to the development of assessment proposals outlined in: 'A report on assessing and reporting student outcomes in Asian languages (Japanese and Indonesian)' (Hill, Iwashita, McNamara, Scarino \& Scrimgeour, 2004) and in consultations undertaken in the SAALE study, participants consistently emphasised the need for any statement about students' achievements in learning languages to be sensitive to the specific language, to the diverse groups of learners that comprised the population of learners of the particular language, and to the conditions of learning that pertain in the particular state and school policy context.

Throughout their history of development in Australia and indeed in diverse contexts of languages education internationally, curriculum and assessment frameworks have been used for different purposes, including system accountability, developing and improving teaching and learning, assessment and reporting and, most recently, in an era of increasing 
international comparison and portability, they are being proposed for international referencing of standards and credentials (for example, Council of Europe, 2001, regarding the use of the Common European Framework of Reference). Their generic nature widens the interpretive possibilities related to their use and as such raises questions about their use and usefulness in relation to their intended purposes (see Fulcher, 2008).

In summary, the discussion of context points to the dynamic movement of students that is changing the linguistic and cultural populations in particular contexts and therefore the place of particular languages and multilingualism in that context. In each particular context it is important for the educational system to recognise the different dimensions of diversity that result from the different histories, policies and status of particular languages. In Australia the critical dimensions are learner background and time-on-task. The changing population brings a diversity of needs, interests, motivations, desires, and expectations with respect to language learning. However, the persistently generic nature of curriculum and assessment frameworks for languages imposes a form of standardisation that pre-structures language learning and what counts as learner achievements and fails to recognise appropriately the very different achievements that can be expected of different sub-groups of the population. Furthermore, the shaping force of expectations influences the actual achievements. Frameworks are necessarily idealisations and abstractions that eliminate the detail of particular contexts. This decontextualisation, however, detracts from the interpretability and meaningfulness of descriptions of achievements.

\section{RATIONALE FOR ACKNOWLEDGING THE DIVERSITY OF LEARNER ACHIEVEMENTS}

\section{THE QUESTION OF LEGITIMATE ACHIEVEMENTS}

In the context described above, the languages education field in Australia has not been in a position to respond adequately to the question of what it is that students can legitimately be expected to achieve in learning particular languages, in $\mathrm{K}-12$. This question is of interest to policy makers who invest in language learning (through language programs such as the National Asian Languages and Studies in Schools Program (Department of Education, Employment and Workplace Relations [DEEWR], n.d) and seek evidence of return on investment in terms of student learning. It is also of interest to educational systems that are accountable for language program development and student learning outcomes and that are interested in evidence of improvements. It is of interest to parents, who wish to know that their children's learning is fruitful. It is of interest to teachers and school communities, who wish to see worthwhile results from their teaching efforts and who also, perhaps most importantly, wish to have a common reference point for making judgments about student learning in particular languages, within a K-12 developmental perspective. It is of interest to students, who are naturally motivated by success in their language learning and by seeing a pathway or direction for their achievements both here and now and in at least the immediate

238 A RATIONALE FOR ACKNOWLEDGING THE DIVERSITY OF LEARNER ACHIEVEMENTS IN LEARNING PARTICULAR LANGUAGES IN SCHOOL EDUCATION IN AUSTRALIA 
future along the K-12 trajectory. It is of interest to researchers interested in conceptualising the nature of descriptions of learner achievements, their development and use in the context of language learning.

All of these interested parties working at the policy and systems level, at the teaching and learning level, and in ongoing research seek a response to the question of learner achievements that is seen as legitimate when it does justice to all involved. They recognise that achievements will be different for different languages, for different learner groups and for different amounts of time spent on language learning. These are the major structural variables relevant to language learning in the Australian context and variation in relation to these will necessarily lead to differences in the nature and scope of learner achievements. Failure to take these variables into account renders the descriptions of learner achievements less 'real' or realistic.

The aim of the SAALE study was to investigate these variables as a basis for describing student achievements in four different languages, for diverse learner groups that form, for each particular language, the population of students for whom there is a significant difference in achievements. For example, with the current population of Chinese language learners in Australia, as evidenced in the SAALE study, there are differences in the achievements of first language learners, second language learners and those learners who have some background in Chinese. With the current population of Indonesian language learners in school language learning in Australia, only one of the groupings is relevant, namely, second language learners. It is in this sense that the descriptions developed from the SAALE study can be described as context-sensitive; that is, they are sensitive to the specific language, to the learner background with respect to the target language, and to the conditions of learning, notably time-on-task.

The SAALE study did not investigate aspects of context that are program-specific, for example, the availability and use of particular resources, the approach to teaching and learning, or the background and experience of the teacher. These aspects also influence learner achievements but not in the same overall structuring way that the variables investigated in the SAALE study do. The SAALE descriptions are considered to be legitimate in the sense that they seek to describe the recognised differences in achievements that pertain to the variables investigated.

I now discuss, in turn, the specific rationale for acknowledging these differences at the policy and educational systems level, the teaching and learning level and in research. At each level, it is important to go beyond a focus on reporting for accountability purposes towards a focus on understanding learner achievements in language learning developmentally across the K-12 continuum.

A RATIONALE FOR ACKNOWLEDGING THE DIVERSITY OF LEARNER ACHIEVEMENTS IN LEARNING PARTICULAR LANGUAGES IN SCHOOL EDUCATION IN AUSTRALIA 239 


\section{POLICY AND EDUCATIONAL SYSTEMS LEVEL}

There are marked differences in policy settings nationally and across states and territories of Australia with regard to language in education and these shape curriculum policies and practices. There are differences in the languages that are included in the languages education program, in entry and exit points across the $\mathrm{K}-12$ continuum, in the amount of time available per week, for language learning in the program orientation (for example, programs with a focus on language acquisition as opposed to programs with a focus on sensitisation to culture, especially at primary level), in aims and expectations, and in the provisions for articulation in sequences of learning from primary to secondary level programs in the same language for learners who begin the study of a language at primary level. Despite this variability, all curriculum and assessment frameworks are generic in the ways described above.

At the level of national and state policy and systems, the availability of descriptions of achievements that are sensitive to the context, at least to some extent, would ensure that policy makers and systems develop appropriate policies and establish national and state goals and expectations that are realistic and relevant to language learning in the particular context. With an appropriate set of policies, goals and expectations they would have the bases for gathering data to respond in meaningful ways to accountability questions about return on investment and the various aspects of language-in-education policy and curriculum policy provisions. A curriculum and assessment framework that acknowledged the diversity of student achievements would provide a baseline and reference point for monitoring and further planning.

\section{THE TEACHING AND LEARNING LEVEL}

The diverse policy settings discussed above result in highly diverse teaching, learning and assessment practices and diverse expectations about learner achievements. Teacher expectations are essentially local in that teachers are necessarily influenced by their own educational preparation and experience in their local context. Teacher expectations influence their views of learners, learning and, most importantly, development in language learning. They also influence their interpretations of their local (generic) curriculum and assessment frameworks for language learning, and the judgments they make about student achievements, progress and further learning.

Descriptions of learner achievements have the potential to act as a common reference point for teachers in understanding their own judgments of student achievements. When these are generic, there is scope for a wider span of interpretations of student achievements and for masking actual differences in student achievements, as evidenced in the SAALE study. This masking has the potential to influence the actual development of student achievement. For example, if L2 learners' achievements in Chinese language learning were referenced against descriptions of achievements of L1 learners they would potentially be seen as under-performing. On the other hand, if the

240 A RATIONALE FOR ACKNOWLEDGING THE DIVERSITY OF LEARNER ACHIEVEMENTS IN LEARNING PARTICULAR LANGUAGES IN SCHOOL EDUCATION IN AUSTRALIA 
achievements of L1 learners were referenced against descriptions of achievements for L2 learners, they would potentially be seen as performing well, although they would not necessarily be performing at the level of their maximum potential. These would be false comparisons, however, because the learning trajectory for the two groups is different. (See Leung \& Lewkowicz, 2008 and Leung \& Rea-Dickins, 2007 for a discussion of this issue in relation to English as a Second Language and English L1). Throughout the SAALE study there was evidence of teachers talking about the ways they had found for compensating for differences in student achievements. In assessing students' responses they readily recognised the learners' background profiles and intuitively "adjusted" their expectations of learner achievements accordingly. With this kind of "adjustment" it becomes difficult to develop among teachers common understandings of achievements at any particular time and over time across the K-12 trajectory.

Without common reference points, achievements can only be considered as local and there is no mechanism available for teachers to consider the achievements of their own students in the context of learning beyond their immediate local one and in the context of long-term, K12 trajectories.

The issue of expectations and achievements is rendered even more complex when we consider the mediated nature of student achievements (Lantolf \& Frawley, 1992). As Nicholas (2000, p.86) states:

The critical point is the acknowledgement that the achievement of learners on proficiency tests is not an independent measure of the difficulty of the language. Rather, ... language proficiency is a 'mediated' reflection of the engagement of the human beings (teachers and learners) in the overall process. It is not the 'language' that is tested by the proficiency test but the total experiences of the human beings involved (in both the learning/teaching and in the test development).

In this way descriptions of student achievements have the potential not only to define the developmental trajectory for learners, but to actually create or shape it. Teachers need to better understand not only the nature, scope and quality of student achievements in the context of K-12 trajectories of learning and development, but also the way in which their interpretation and construction of achievements has the power to shape them. With at least some sensitivity to context, descriptions of achievement become more meaningful to teachers as a reference point for their work.

\section{ONGOING RESEARCH}

Given the complexity of the issues that need to be taken into consideration in conceptualising and describing the achievements of diverse learners learning particular languages $\mathrm{K}-12$, and the need for better understanding of learner achievements (Scarino, 2000), it is essential that research inform the processes of developing and using the descriptions. In order to maximise

A RATIONALE FOR ACKNOWLEDGING THE DIVERSITY OF LEARNER ACHIEVEMENTS IN LEARNING PARTICULAR LANGUAGES IN SCHOOL EDUCATION IN AUSTRALIA 241 
the usefulness of these descriptions, research into the impact of particular contextual variables is also needed.

Ongoing research is needed into the conceptualisation of the construct of 'communicative language use' and its expansion to capture multilingual capabilities; the process of development of descriptions of achievement, and the use of such descriptions by teachers and other users.

\section{Conceptualisation of the construct}

In relation to the conceptualisation of the construct, three dimensions need to be taken into account: the conceptualisation of 'communicative language use', of progression, and of the nature of proficiency or achievement. The changing context of multilingualism in contemporary times is challenging conceptualisations of language, culture, learning, the goals of learning and learner achievements. Any description of learner achievements must begin with the construct of communicative language use. Bachman and Palmer (2010), for example, have further elaborated their model of communicative language ability to consider non-reciprocal and reciprocal language use. Cook (2010) has elaborated a view of multicompetence that recognises the development of a multilingual capability as the essential goal of language learning. Developing this capability includes competencies beyond the traditional conception of communicative language teaching as interactive/transactional communication in the target language, removed from social, historical and cultural contexts. Kramsch (2009) highlights that learning a language is not a monolingual activity and she too describes the multilingual capabilities of the multilingual subject. Garcia (2009) describes bilingual/multilingual practices and the kinds of pedagogies and assessments needed to do justice to capturing students' capabilities. These expansions of the construct also shape the conceptualisation of learner achievements. They are not reflected in current descriptions of learner achievements. In addition to the conceptualisation needed to understand the capabilities specifically in relation to language learning, K-12, research is needed to establish the ways in which these capabilities are evidenced in students' actual achievements.

In considering the development of language learning capabilities of learners, $\mathrm{K}-12$, it is necessary to acknowledge that language learning (whether the language is being learned as an L1 in a new context of learning, or as an L2, or as a language in which the learner has some home background), is intertwined with the learners' general cognitive and social development, and this needs to be taken into account. (See Hulstijn, 2011 for a discussion of this point in relation to adult L1 and L2 proficiency). In other words, it is necessary to conceptualise the construct of 'development' and to characterise the increasing complexity of language use and language learning. Research on students' actual language development is needed in the context of diverse programs. Furthermore, the development of descriptions of K-12 language learning also interfaces with constructs of 'proficiency', 'achievement' and 'standards' (Kramsch, 2006). A 'proficiency' orientation (such as in the Common European Framework of Reference) focuses on what students

242 A RATIONALE FOR ACKNOWLEDGING THE DIVERSITY OF LEARNER ACHIEVEMENTS IN LEARNING PARTICULAR LANGUAGES IN SCHOOL EDUCATION IN AUSTRALIA 
can do in the target language irrespective of the context in which it is acquired; it describes the progression of achievements as an absolute scale. An 'achievement' orientation, as proposed in the SAALE study, focuses on what students can do in the target language based on the distinctive context of the program, specifically in relation to its diverse learners and time-on-task. The contrast in the style of descriptions that results from these orientations can be seen in the descriptions included in the appendix.

The interaction of the three dimensions renders the conceptualisation of the construct particularly complex and difficult to operationalise. For example, in the SAALE study a deliberate decision was made to retain a relatively traditional conceptualisation of the construct of communicative language use, so as not to introduce in the test development unfamiliar dimensions of language learning to which teachers may not have introduced their students. This decision necessarily means that there are aspects of learner achievements that were simply not elicited and described. (See Elder, Kim \& Knoch and Kohler, this volume.)

\section{The process of developing descriptions of achievement}

Many issues can be raised in relation to the processes of development and validation of descriptions of learner achievement in language learning, including the language-specific nature of achievements in languages education, the overall assessment bases (that is, intuitive or empirical), instrumentation, sampling, marking, analysis and scaling. (See Elder, Kim \& Knoch, this volume.) The SAALE study investigated two contextual variables that structure languages education and achievements in the Australian context and incorporated the findings from the study in the development of descriptions of learner achievements. However, limitations arise from the single iteration of the study, with a single set of assessment tasks, limited piloting and limited sample size. Validation was not based on use of the descriptions of achievement, but was limited to a process of consultation with teachers. Nevertheless, the study provided an empirical base at least for the development of the descriptions themselves. Many more studies are needed specifically examining the process of development and validation of descriptions of achievement.

Many processes of developing descriptions of achievement, including that used in the SAALE study, incorporate the views of teachers as those who work most closely with students in the K-12 context. (See McKay, 1992, 2005, 2006). This means that the process necessarily needs to include consideration of the variation in expectations held by teachers, which come from their own interpretive frameworks. Inevitably the process involves a relationship between research and development, which itself needs to be investigated.

\section{The use of descriptions of learner achievement by teachers and others}

With respect to the use of descriptions of learner achievement, no research specifically in relation to the learning of languages other than English across the K-12 continuum has been

A RATIONALE FOR ACKNOWLEDGING THE DIVERSITY OF LEARNER ACHIEVEMENTS IN LEARNING PARTICULAR LANGUAGES IN SCHOOL EDUCATION IN AUSTRALIA 243 
undertaken in Australia, at either a systemic or individual teacher level (see Breen et al., 1987 for an account of an implementation study related to ESL in Australia and a recent report by Macqueen, Harding \& Elder, 2011, on the Victorian Essential Learning Standards [VELS]). This too is an absence that needs to be addressed. Finally, with respect to the use of descriptions of learner achievement, it is essential to take into account assessment literacy among policy makers and teachers (see Inbar-Lourie, 2008).

\section{CONCLUSION}

The value of descriptions of $\mathrm{K}-12$ student achievements in learning languages resides in the fact that they provide a response to the question of nature, scope and quality of learner achievements that result from sequences of learning. This information is needed by different stakeholders for a range of reasons.

Policy makers and systems need to respond to accountability requirements and need wellfounded bases for their languages education policies and related curriculum policy development work. Teachers need to move beyond episodic and towards $\mathrm{K}-12$ perspectives of language learning in order to develop better understanding of the growth and development over time in the learning of specific languages on the part of diverse groups of learners. This is a crucial part of developing their expectations and expanding their interpretive frameworks which are influential in mediating teaching, learning, assessment and achievement. Researchers need to continue the investigation of constructs and processes of development, monitoring and use of descriptions of achievement to ensure sound bases for language learning in schools.

In the Australian context of languages education, descriptions that do not take into account acknowledged differences across languages, across groups of students with diverse linguistic and cultural backgrounds and affiliations with the target language, and across program conditions such as time-on-task, are too generalised to be meaningful and of value to the diverse users. They do not do justice to the diversity of learner achievements and as such cannot and will not be seen as legitimate. As Spolsky (2008) has stated in his reflection on language assessment in historical and future perspectives 'simple unidimensional scales ... (need to be) replaced by complex profiles showing the wide range of plurilingual proficiency of anyone tested'. In the changing context of multilingualism a richer qualitative understanding of the nature and scope of achievements that are sensitive to diverse contexts becomes an important part of any goal for improving the nature, scope and quality of language learning.

244 A RATIONALE FOR ACKNOWLEDGING THE DIVERSITY OF LEARNER ACHIEVEMENTS IN LEARNING PARTICULAR LANGUAGES IN SCHOOL EDUCATION IN AUSTRALIA 


\section{REFERENCES}

Australasian Curriculum, Assessment and Certification Authorities (ACACA) (1991). National Assessment Framework for Languages at Senior Secondary Level (NAFLSSL). Hosted by the Senior Secondary Assessment Board of South Australia, http://www.saceboard.sa.edu.au/ccafl/.

Australasian Curriculum, Assessment and Certification Authorities (ACACA) (2001). The Collaborative Curriculum and Assessment Framework for Languages (CCAFL). Hosted by the Senior Secondary Assessment Board of South Australia, http://www.saceboard.sa.edu.au/ccafl/.

Bachman, L. \& Palmer, A. (2010). Language assessment in practice. Oxford: Oxford University Press.

Ball, S. (2000). Performativities and fabrications in the education economy: towards a performative society? Australian Educational Researcher, 27(2), 1-23.

Board of Studies of Victoria. (1995). Curriculum and Standards Framework - Languages other than English (CSF). Melbourne. Board of Studies of Victoria.

Breen, M.P., Barratt-Pugh, C., Derewianka, B., House, H., Hudson, C., Lumley, T. \& Rohl, M. (1997). Profiling ESL children. How teachers interpret and use national and state assessment frameworks [Vol.1]. Canberra: Department of Employment, Education, Training and Youth Affairs.

Brinton, D.M., Kagan, O. \& Bauckus, S. (Eds). (2008). Heritage language education. A new field emerging. New York. Routledge.

Clyne, M. (1991). Community languages. The Australian experience. Cambridge. Cambridge University Press.

Clyne, M. (2005). Australia's language potential. Sydney: University of NSW Press.

Cook, G. (2010). Translation in language teaching. Oxford: Oxford University Press.

Council of Europe. (2001). Common European Framework of Reference for Languages (CEFR): Learning, teaching, assessment. Cambridge: Cambridge University Press.

Curriculum Corporation of Australia (1994). Languages other than English: a curriculum profile for Australian schools. Melbourne: Curriculum Corporation.

Department of Education, Employment and Workplace Relations. National Asian Languages and Studies in Schools Program (NALSSP). (n.d.). Retrieved 25 March 2012, from http://www.deewr.gov.au/schooling/nalssp/Pages/default.aspx.

Elder, C. (2000a). Learner diversity and its implications for outcomes-based assessment. In C. Elder (Ed.) Defining standards and monitoring progress in languages other than English. Guest edited issue of the Australian Review of Applied Linguistics, 23(2), 36-61.

Elder, C. (2000b). Outing the 'native speaker': The problem of diverse learner backgrounds in foreign language classrooms. Language, Curriculum and Culture, 13(1): 86-108.

Elder, C., Kim, H. \& Knoch, U. (this issue). Documenting the diversity of learner achievements in Asian languages using common measures.

Fulcher, G. (2008). Evaluating language quality. In E. Shohamy \& N.H. Hornberger (Eds) Encyclopaedia of language and education: Language testing and assessment, 7, 157-176.

Garcia, O. (2009). Bilingual education in the $21^{\text {st }}$ century. A global perspective. Chichester, West Sussex. Wiley Blackwell.

A RATIONALE FOR ACKNOWLEDGING THE DIVERSITY OF LEARNER ACHIEVEMENTS IN LEARNING PARTICULAR LANGUAGES IN SCHOOL EDUCATION IN AUSTRALIA 245 
Hill, K., Iwashita, N., McNamara, T., Scarino, A., \& Scrimgeour, A. (2004). A report on assessing student outcomes in Asian languages (Japanese and Indonesian). Report to the Australian Government Department of Education, Science and Training.

Hulstijn, J.H. (2011). Language proficiency in native and nonnative speakers: an agenda for research and suggestions for second-language assessment. Language Assessment Quarterly, 8, 229-249.

Inbar-Lourie, O. (2008). Constructing a language assessment knowledge base: A focus on language assessment courses. Language Testing, 25(3), 385-402.

Johnstone, R. (2000). Context-sensitive assessment of modern languages in primary (elementary) and early secondary education: Scotland and the European experience. Language Testing, 17(2), 123-143.

Kramsch, C. (2006). From communicative competence to symbolic competence. Modern Language Journal, 90, 249-252.

Kramsch, C. (2009). The multilingual subject. Oxford: Oxford University Press.

Lantolf, J. \& Frawley, L. (1992). Proficiency: understanding the construct. Studies in Second Language Acquisition, 10(2), 181-196.

Leung, C. \& Lewkowicz, J. (2008). Assessing diverse populations. In E. Shohamy \& N.H. Hornberger (Eds). Encyclopedia of language and education. Volume 7. Language testing and assessment $\left(2^{\text {nd }}\right.$ ed.) (pp. 301-317). New York: Springer.

Leung, C. \& Rea-Dickins, P. (2007). Teacher assessment as policy instrument: contradictions and capacities. Language Assessment Quarterly, 4(1), 6-36.

Lo Bianco, J. (2010). The struggle to retain diversity in languages education. In A.J. Liddicoat and A. Scarino (Eds). Languages in Australian education: problems, prospects and future directions (pp. 97-108). Newcastle Upon Tyne. Cambridge Scholars.

Lo Bianco, J. (2009). Second languages and Australian schooling. Melbourne: Australian Council for Educational Research.

Luke, A. (2011). Generalizing across borders: policy and the limits of educational science. Educational Researcher, 40(8), 367-377.

Macqueen, S., Harding, L.\& Elder, C. (2011). Investigating the validity of the ESL VELS student data (Final report). Melbourne: Language Testing Research Centre.

McNamara, T. \& Elder, C. (2010). Beyond scales. In A.J. Liddicoat and A. Scarino (Eds). Languages in Australian education: problems, prospects and future directions (pp.193-202). Newcastle Upon Tyne. Cambridge Scholars.

McKay, P. (1992). ESL Development: language and literacy in schools project. Volumes 1 and 2, National Languages and Literacy Institute of Australia: Melbourne, Victoria.

McKay, P. (2005). Research into the assessment of school age language learners. Annual Review of Applied Linguistics, 25, 243-263.

McKay, P. (2006). Assessing young language learners. Cambridge: Cambridge University Press.

Mercurio, A. \& Scarino, A. (2005). Heritage languages at upper secondary level in South Australia: A struggle for legitimacy. International Journal of Bilingual Education and Bilingualism, 8, $2 \& 3,145-159$.

246 A RATIONALE FOR ACKNOWLEDGING THE DIVERSITY OF LEARNER ACHIEVEMENTS IN LEARNING PARTICULAR LANGUAGES IN SCHOOL EDUCATION IN AUSTRALIA 
Ministerial Council on Education, Employment, Training and Youth Affairs (MCEETYA) 2008. Melbourne declaration on educational goals for young Australians. Melbourne. MCEETYA. Retrieved 25 March, 2012, from http://www.mceecdya.edu.au/verve/_resources/National_Declaration_on the Educational_Goal s for Young Australians.pdf.

Nicholas, H. (2000). Is there progress in standards? Australian Review of Applied Linguistics, 23(2), 79-88.

Orton, J. (2008). The current state of Chinese language education in Australian schools. Melbourne: Education Services Australia.

Peyton, J.K., Ranard, D. A. \& McGinnis, S. (Eds.) (2001). Heritage languages in America. McHenry, IL: Centre for Applied Linguistics and Delta Systems Co.

Scarino, A. (1995). Language scales and language tests: development in Languages other than English. Melbourne Papers in Language Testing, 4(2), 30-42.

Scarino, A. (2000). Complexities in describing and using standards in languages education in the school setting: whose conceptions and values are at work? Australian Review of Applied Linguistics, 23(2), 7-20.

Scarino, A. (2008). The role of assessment in policy-making for languages education in Australian schools: a struggle for legitimacy and diversity. Current Issues in Language Planning, 9(3), 344-362.

Scarino, A. (2010). Language and languages in the curriculum. In A.J. Liddicoat and A. Scarino (eds). Languages in Australian education: problems, prospects and future directions (pp.157-178). Newcastle Upon Tyne: Cambridge Scholars.

Scarino, A., Elder, C., Iwashita, N., Kim, S. H. O., Kohler, M. \& Scrimgeour, A. (2011). Student achievement in Asian languages education. Part 1: Project Report. Report prepared for the Department of Education, Employment \& Workplace Relations (DEEWR). Available from www.saale.unisa.edu.au.

Scarino, A., Vale, D., McKay, P., \& Clark. J. (1989). The Australian Language Levels (ALL) Guidelines. Canberra. Curriculum Development Centre.

Spolsky, B. (2008). Historical and future perspective. In E. Shohamy \& N.H. Hornberger (Eds). Encyclopedia of language and education. Volume 7: Language testing and assessment ( $2^{\text {nd }}$ ed.) (pp.445-454). New York: Springer.

Stroud, C. \& Heugh, K. (2011). Languages in education. In R. Mesthrie (ed). Cambridge handbook of sociolinguistics (pp.413-429). Cambridge: Cambridge University Press.

Stroud, C. \& Wee, L. (2010). Language policy and planning in Singaporean late modernity. In L. Lim, A. Pakir \& L. Wee. (Eds) English in Singapore: modernity and management (pp.181-204). Singapore: NUS Press. 


\section{APPENDIX}

\section{PROFICIENCY-ORIENTED DESCRIPTIONS: EXAMPLE - COMMON EUROPEAN FRAMEWORK}

\section{OFREFERENCE}

Common reference levels: global scale

\begin{tabular}{|l|c|l|}
\hline Independent & B2 & $\begin{array}{l}\text { Can understand the main ideas of complex text on both } \\
\text { concrete and abstract topics, including technical discussions in } \\
\text { his/her field of specialisation. Can interact with a degree of } \\
\text { fluency and spontaneity that makes regular interaction with } \\
\text { native speakers quite possible without strain for either party. } \\
\text { Can produce clear, detailed text on a wide range of subjects } \\
\text { and explain a viewpoint on a topical issue giving the } \\
\text { advantages and disadvantages of various options. }\end{array}$ \\
\cline { 2 - 3 } & B1 & $\begin{array}{l}\text { Can understand the main points of clear standard input on } \\
\text { familiar matters regularly encountered in work, school, leisure, } \\
\text { etc. Can deal with most situations likely to arise whilst } \\
\text { travelling in an area where the language is spoken. Can } \\
\text { produce simple connected text on topics which are familiar or } \\
\text { of personal interest. Can describe experiences and events, } \\
\text { dreams, hopes and ambitions and briefly give reasons and } \\
\text { explanations for opinions and plans. } \\
\text { Note: Common reference levels are also available for 'basic } \\
\text { user' and 'proficient user'. } \\
\text { (Council of Europe, 2001, p.24) }\end{array}$ \\
\hline
\end{tabular}

248 A RATIONALE FOR ACKNOWLEDGING THE DIVERSITY OF LEARNER ACHIEVEMENTS IN LEARNING PARTICULAR LANGUAGES IN SCHOOL EDUCATION IN AUSTRALIA 


\section{ACHIEVEMENT-ORIENTED DESCRIPTIONS: EXAMPLE - SAALE}

Year 10 Second Language Learners - Writing - High

\section{Forms and Structures}

Students use basic Chinese word order consistently, with a range of verb-object and adjectival predicates, adverbial constructions of time and prepositional phrases used to describe time, location, or participants in events. Number-measure phrases are used effectively, especially when referring to familiar subject matter. A range of modal verbs are used to express possibility or intention (e.g. 可以, 要, 会, 应该). Students express past tense using, for example, 了, time phrases, adverbs of frequency, for example, 有时候. Prepositional phrases using 跟, 从, 对, etc., are used to describe or elaborate on preferences, participants, time, or place (e.g. 我对音乐感兴趣). Students provide additional details using more complex structures such as attributive or relative clauses (e.g. 我最喜欢的课也是中文), or comparisons using 比, and 跟一样 (e.g. 他的功夫比我的好, 我的功夫和他的一样, 你的学校比我的大). Information is presented using coordinating conjunctions (e.g. 和, 但是, and 又... 又...) to link ideas, adverbs 也, 都 to describe the range of participants or actions, and subordinating conjunctions (e.g. 因为 ...) to relate ideas, or justify opinions and reasons (e.g. 我喜欢科学因为很有意思).

Errors occasionally occur because of an overextension of a word (or character) meaning, for example, ideas related to future aspirations are often expressed as 我想, rather than 我希望.

Students occasionally use English word order (e.g. placement of time 我们上课九点和下课三点牛) and overuse the verb to be (是) with adjectives and number phrases (e.g. 我是十六岁).

\section{Discourse}

Students organise ideas into single paragraphs with each topic addressed in one or two sentences. Students display awareness of the audience by providing appropriate greetings/salutations and closures to correspondence, making enquiries using 什 ${ }^{-}$or 为什么, and occasionally asking questions in response to statements (e.g. 为什么你喜欢这个?). 
Year 10 Background Language Learners - Writing - High

\section{Forms and Structures}

Students use a range of sentence structures with ideas expressed in a natural manner, for example, using the particle 的for relative and attributive clauses (e.g.在... 长大的, 六节课都在不同的教室). They use a range of constructions to express more detailed meanings, for example, to express duration 过两个月澳州式的生活, to make comparisons 就像上海的天气, 还有一点不同, to express the extent of a situation using indefinite pronouns (e.g. 我什 - 课都喜欢), to describe a sequence of events or simultaneous actions using, for example, 放学以后 ...; 一边... 一边...; 在 ... 的时候; 一 ...就 .... and to express future intention using modal verbs and adverbs (e.g. 将来, 就会), and past experience using aspect marker 过 and the tense marker 了.

They express conditionality using 如果 and 要是, and express contrast using 虽然... 但是... and 不过, and express cause and effect using 因为, 为了... and 一... 就...They use the particle 了 or 是...的 to add emphasis (e.g. 就行了, 悉尼最好玩了).

Errors in students' expression occasionally occur because of overgeneralisation of a rule or application of oral speech patterns in their writing.

\section{Discourse}

Ideas are clearly sequenced and information is presented in paragraphs with a clear relationship between ideas. Writing is presented in an appropriate format, with recognition of the audience in greeting and closure, and engagement through direct reference to the reader in the text (e.g. 我 péi (陪) 你一起去).

Note: Descriptions are included for writing only but are also available for oral and reading; descriptions are included for 'forms and structures; and 'discourse' but are also available for 'content', 'vocabulary', and 'characters'.

(Scarino et al., 2011, Part 2, pp. 17-18 and 25-26)

250 A RATIONALE FOR ACKNOWLEDGING THE DIVERSITY OF LEARNER ACHIEVEMENTS IN LEARNING PARTICULAR LANGUAGES IN SCHOOL EDUCATION IN AUSTRALIA 